УДК 342.932.4 + 338.816

DOI: 10.14529/iimj160105

ЭКОНОМИЧЕСКАЯ БЕЗОПАСНОСТЬ КОМПАНИИ - ИСТОЧНИК

КОНКУРЕНТНОГО ПРЕИМУЩЕСТВА

\author{
Н.Н. КОТОВА \\ Южно-Уральский государственный университет (Челябинск)
}

В статье рассматривается актуальная проблема деятельности организации, связанная с её экономической безопасностью. Анализируется роль коммерческой разведки в концепции «раннего предупреждения» от стратегических рисков. В качестве инструмента исследования рынка в предлагаемой концепции используется стратегический бенчмаркинг. Проведение коммерческой разведки не только способствует снижению риска компании, функционирующей в рынке конкретного товара, но и усиливает её экономическую безопасность, превращая последнюю в источник устойчивого конкурентного преимущества. В статье перечисляются отдельные виды экономической деятельности организации, а также внешние и внутренние факторы, на них влияющие.

Наиболее значимым моментом при внедрении концепции «раннего предупреждения» и реализации методов коммерческой разведки является выбор организацией проактивной стратегии, которая предполагает не только безусловную ориентацию на изменяющиеся условия бизнес-среды и возможный отказ от получения текущих прибылей в пользу долгосрочного результата, но и требует совмещения в решении двух достаточно противоречивых задач: защиты функционирующих активов организации и сохранения её конкурентной позиции в рынке (с учетом его динамичности).

Ключевые слова: экономическая безопасность организации, коммерческая разведка, стратегический риск, устойчивое конкурентное преимущество, капитализация компании.

«Для большинства стран с развитой экономикой вторая половина XX столетия была периодом «Великого спокойствия», как окрестили его некоторые экономисты, характеризовавшимся безмятежным высоким ростом в условиях низкой инфляции. В результате господствовавшие экономические представления либо вовсе игнорировали кризисы, либо рассматривали их как проблему, свойственную менее развитым экономическим системам» $[11$, c.13]. Начавшийся в XXI веке экономический и финансовый кризис, способствующий дисбалансу в развитии мировой экономики, потребовал не только изменения порядка управления глобальными экономическими процессами, но и пересмотра подхода к изучению функционирования хозяйствующего субъекта (компании, организации, фирмы) в рынке. Согласно высказыванию Питера Друкера «все существующее со временем устаревает» [6, с.13]. Совершенствуются инстру- менты исследования рынка, методики анализа деятельности его экономических агентов, критерии их эффективности. Эффективно работающей организацией считается та, у которой за период её деятельности возрастает стоимость бизнеса, то есть происходит процесс капитализации, связанный с инновациями.

Подлинная инновация создаваемой ценности компании предполагает выход организации за общепринятые рамки, определяющие принципы конкуренции в конкретной отрасли. В то же время большинство компаний, ограничивающие себя установленными рамками, начинают использовать схожие стратегии, сравнимые по одним и тем же базовым показателям, что ставит их в равные условия с соперничающими организациями. В этой ситуации происходит ужесточение конкуренции, особенно на тех товарных рынках, где рост спроса на продукцию (услуги) замедляется (что характерно для «зрелых» отраслей или 
отраслей, находящихся на стадии спада). Меняются и границы конкуренции: современная компания конкурирует не только с другими организациями своей отрасли, но и с компаниями тех отраслей, которые производят альтернативные продукты и услуги. Подобные тенденции способствуют формированию нового рыночного пространства. Давление конкуренции становится еще существеннее благодаря глобализации рынков, возрастающей роли инновационных технологий, быстрым структурным изменениям, происходящим в отраслях, где функционирует компания [4,2].

Перечисленные факторы неопределенности приводят к росту бизнес-риска и могут ухудшить рыночное положение компании на перспективу. Понятие риска связано с опасностью и неожиданностью её возникновения. Для любого бизнеса неожиданность разрушительна и может привести не только к потере прибыли и возникновению убытков, но и к реорганизации, a, возможно, и ликвидации компании (критические и катастрофические риски). Снижение риска обеспечивает конкурентная (или коммерческая) разведка, целью которой выступает специфическое исследование рынка, предназначенное для формирования и внедрения проактивной стратегии. Разработка такой стратегии позволит установить стратегические риски и вероятность стратегического успеха (шансы), используя концепцию «раннего предупреждения» [5, с.10]. Функцию реализации выбранной стратегии на уровне компании выполняет стратегический контроллинг, обеспечивая переход от стратегического планирования к стратегическому управлению.

Снижению риска в деятельности компании способствует проведение коммерческой разведки. Основное предназначение коммерческой разведки - обеспечить безусловное превосходство компании над конкурентами. При этом проведение конкурентной разведки должно: препятствовать неожиданным действиям конкурентов; способствовать получению информации превентивного порядка о конкурентах и состоянии рыночного пространства; выявлять наиболее уязвимые слабые стороны конкурентов с целью снижения их конкурентоспособности и ослабления конкурентной позиции по сравнению с позицией, занимаемой компанией. Благодаря коммерческой разведке реализуется концепция «раннего предупреждения» от стратегических неожиданностей на рынке конкретного товара. Это с одной стороны. С другой стороны, коммерческая разведка - это эффективный катализатор изменений рыночного пространства $[3,7,10]$.

В качестве инструмента исследования рынка используется стратегический бенчмаркинг, который оказывает влияние прежде всего на проектирование долгосрочных конкурентных моделей компании. Стратегический бенчмаркинг фокусируется на:

- выделении стратегических групп конкурентов;

- уточнении места компании в одной из стратегических групп конкурентов;

- поиске отраслевых примеров, «образцовой» практики, стандарта, эталонных показателей, используемых для сравнительной оценки;

- изучении опыта и конкурентных стратегий других компаний и выборе оптимальной из них.

Коммерческая разведка не только снижает риски деятельности компании, но и способствует усилению её безопасности, превращая последнюю в источник устойчивого конкурентного преимущества. Основой безопасности компании (организации) выступает экономическая безопасность, гарантирующая сохранение целостности экономической системы компании, стабильности её функционирования и долгосрочной конкурентоспособности, несмотря на действие неконтролируемых факторов бизнес-среды $[1,8,9]$.

Исходя из направлений деятельности организации можно выделить следующие составляющие экономической безопасности:

- информационная безопасность;

- имущественная безопасность;

- кадровая безопасность;

- финансовая безопасность. 
На рисунке 1 показан набор внешних и внутренних факторов, влияющих на экономическую безопасность организации, а также представлен перечень превентивных мер, направленных на предотвращение рисков и опасностей в деятельности организации.

Наиболее значимым моментом при внедрении концепции «раннего предупреждения» и реализации методов коммерческой разведки является выбор организацией проактив- ной стратегии, которая предполагает не только безусловную ориентацию на изменяющиеся условия бизнес-среды и возможный отказ от получения текущих прибылей в пользу долгосрочного результата, но и требует совмещения в решении двух достаточно противоречивых задач: защиты функционирующих активов организации и сохранения её конкурентной позиции в рынке (с учетом его динамичности).

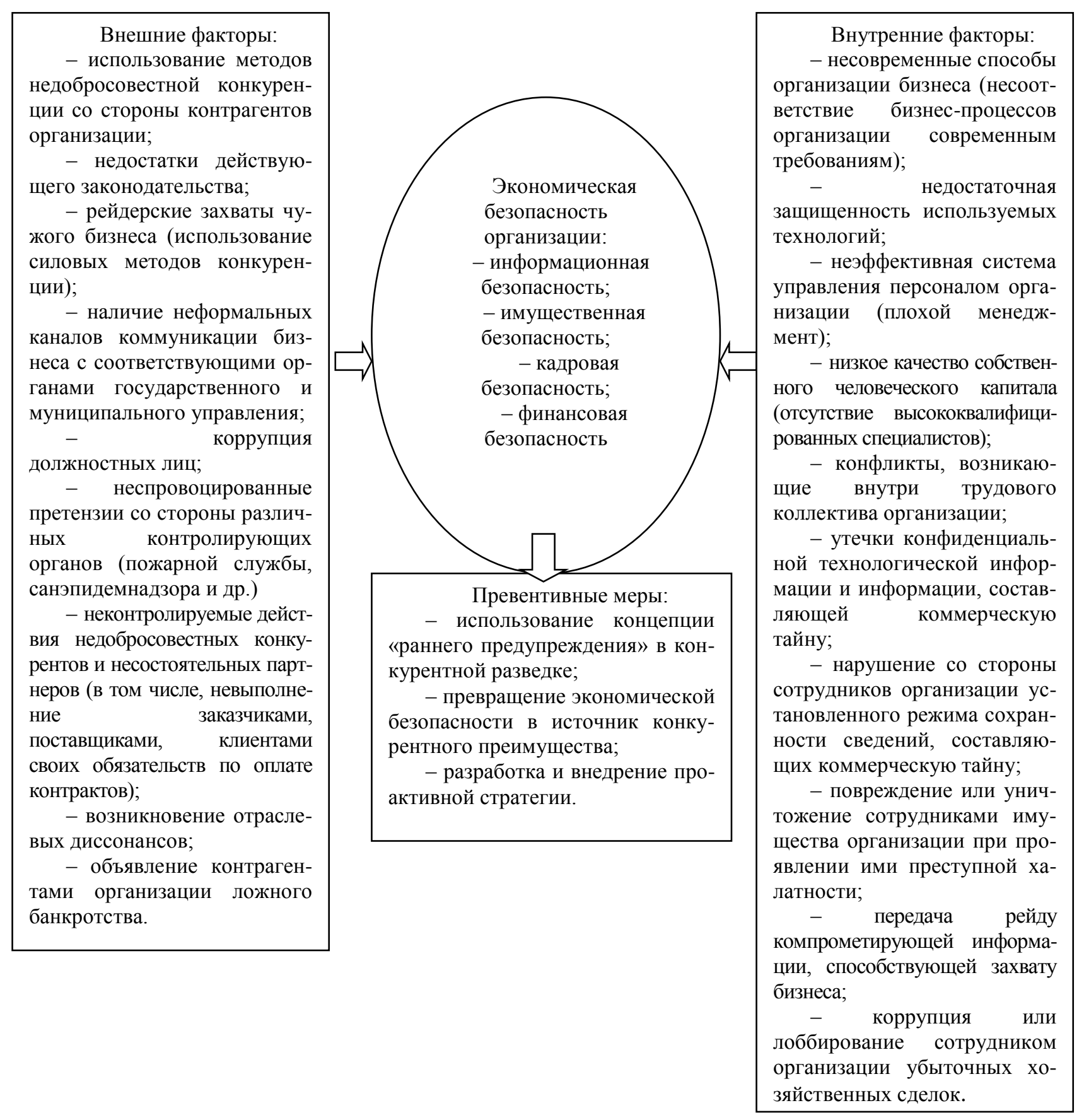

Рис.1. Факторы, влияющие на экономическую безопасность организации 


\title{
Лumepamypa
}

1. Алавердов, А.Р. Управление кадровой безопасностью организаиии: учеб. / А.Р. Алавердов. - М.: Маркет ДС, 2010. - $176 \mathrm{c}$.

2. Бирман, Л.А. Стратегия управления инновационными процессами: учеб. пособие / Л.А. Бирман, Т.Б. Кочурова. - М.: Издательство «Дело», РАНХиГС, 2012. - 144 с.

3. Боган, Кристофер. Бизнес-разведка. Внедрение передовых технологий: пер. с англ. / Кристофер Боган, Майкл Инглии; под общей ред. Б.Л. Ризниченко. - М.: Вериина, 2006. - 368 с.

4. Грант, Р.М. Современный стратегический анализ. 5-е изд. / Пер. с англ. под ред. В.Н. Фунтова. СПб.: Питер, 2008. - 560 c.

5. Джилад, Б. Конкурентная разведка. Как распознать внешние риски и управлять ситуацией. - Спб.: Питер, 2010. - 320 c.

6. Друкер, Питер, Ф. Эффективное управление предприятием.: Пер. с англ. - М.: ООО «И.Д. Вильямс», 2008. $-224 c$.

7. Захаров, О.Ю. Обеспечение комплексной безопасности предпринимательской деятельности. Теория и практика / Захаров О.Ю. - М.: АСТ: Астрель; Владимир: ВКТ, 2008, - 320 с.

8. Коноплева, И.А. Управление безопасностью и безопасность бизнеса: Учебное пособие для вузов / И.А. Коноплева, И.А. Богданов. - М.: ИНФРА-М, 2015. - 448 c.

9. Криворотов, Вадим Васильевич. Экономическая безопасность государства и регионов: учеб. пособие для студентов вузов, обучаюшихся по направлению «Экономика» / В.В. Криворотов, А.В. Калина, Н.Д. Эриашвили. - М.: ЮНИТИ-ДАНА, 2015. - 351 с.

10. Лемке, Г.Э. Коммерческая разведка для конкурентного превосходства / Г.Э. Лемке. - М.: Московская финансово-промышиленная академи, 2011. - 352 c.

11. Рубини, Н. Нуриэль Рубини: как я предсказал кризис: экстренный курс подготовки к будущим потрясениям / Рубини Нуриэль, Мим Стивен; [пер. с англ. В.В. Ильина]. - М.: ЭКСМО, 2011. - 384 с.

12. Bogan, C. Benchmarking for Best Practices: Winning Through Innovative Adaptation / Christopher E. Bogan. - McGraw-Hill, 1994. - 312 p.

13. Drucker, P. Managing for Results: Economic Tasks and Risk-taking Decisions / Peter Ferdinand Drucker. HarperBusiness, 2006. - 256 p.

14. Gilad, Benjamin. Early Warning: Using Competitive Intelligence to Anticipate Market Shifts, Control Risk, and Create Powerful Strategies. - AMACOM, 2003

15. Grant, Robert. Contemporary strategy analysis / Robert M. Grant. - Wiley; 8 edition, 2013. -408 p.

16. Roubini, N. Crisis Economics: A Crash Course in the Future of Finance / Nouriel Roubini, Stephen Mihm. Penguin Books, April 26, 2011. - 368 p.

Котова Надежда Николаевна - кандидат экономических наук, доцент. Южно-Уральский государственный университет (г. Челябинск).

Дата поступления 3 марта 20162.

\section{THE ECONOMIC SECURITY OF A COMPANY - THE SOURCE OF A COMPETITIVE ADVANTAGE}

DOI: $10.14529 /$ iimj160105

\author{
N.N. KOTOVA
}

South Ural State University (Chelyabinsk)

The article deals with the actual problem of economic security of a company. The role of business intelligence in the concept of "early warning" of the strategic risks has been analyzed. The proposed conception uses strategic benchmarking as an instrument of a market research. Conducting business intelligence not only facilitates reducing the risk of a company operating in the market of a particular product but it also enhances its economic security, turning it into a source of a sustainable competitive advantage. Certain types of an economic activity of the company, as well as internal and external factors that affect them have been given.

The most significant moment in the implementation of the "early warning" concept and the implementation of business intelligence methods is the choice of the organization proactive strategy that involves not only the absolute orientation to the changing business environment conditions and the possible refusal to obtain current profits in favor of long-term results, but also requires a combi- 
nation of two quite contradictory objectives: the protection of assets of the organization operating and maintaining its competitive position in the market (taking into account its dynamics)

Key words: economic security of a company, business intelligence, strategic risk, sustainable competitive advantage, capitalization of the company.

\section{References}

1. Alaverdov, A.R. Management of personnel security of the organization: textbook. / R. A. Alaverdov. M.: Market DS, 2010. - 176 p.

2. Birman, L. A. Strategy of innovation processes management: textbook / Birman L. A., Kochurova T. B.. - M.: Publishing House "Delo" Ranepa, 2012. - 144 p.

3. Bogan, Christopher. Business intelligence. The introduction of advanced technologies: translation from English / Christopher Bogan, Michael English; under the general editorship of B. L. Riznichenko. - M.: Vershina, 2006. - 368 p

4. Grant, R. M. Contemporary strategic analysis. 5th edition. Translation from english. under the editorship of V. N. Funtova. - SPb.: Peter, 2008. - $560 \mathrm{p}$

5. Gilad, B. Competitive intelligence. How to identify external risks and to manage the situation. $-\mathrm{SPb}$.: Peter, 2010. -320 p.

6. Drucker, Piter F. The effective management of the enterprise: Translation from English. - M.: LLC "I. D. Williams", 2008. - $224 \mathrm{p}$.

7. Zakharov, O. Y. Maintenance of complex security of entrepreneurship. Theory and practice / Zakharov, O.Y. - M.: AST: Astrel'; Vladimir: VKT, 2008, - 320 p.

8. Konopleva, I. A. Security management and the security business: textbook for universities / I. A. Konopleva, I. A. Bogdanov. - M.: INFRA-M, 2015. - 448 p.

9. Krivorotov, V. V. Economic security of the state and regions: textbook for university students enrolled in Economics / V. V. Krivorotov, A. V. Kalina, N. D. Eriashvili. - M.: UNITY-DANA, 2015. - 351 p.

10. Lemke, G. E. Commercial intelligence for the competitive edge / G. E. Lemke. - M.: Moscow financial-industrial Academy, 2011. - 352 p.

11. Rubini, N. Nouriel Rubini: How I predicted the crisis: emergency training for future crisis / Rubini Nouriel, MIME Steven; [translation from Enflish by V. V. Ilyin]. - M.

12. Bogan, C. Benchmarking for Best Practices: Winning Through Innovative Adaptation / Christopher E. Bogan. - McGraw-Hill, 1994. - 312 p.

13. Drucker, P. Managing for Results: Economic Tasks and Risk-taking Decisions / Peter Ferdinand Drucker. - HarperBusiness, 2006. - 256 p.

14. Gilad, Benjamin. Early Warning: Using Competitive Intelligence to Anticipate Market Shifts, Control Risk, and Create Powerful Strategies. - AMACOM, 2003. DOI: 10.5860/CHOICE.41-3526.

15. Grant, Robert. Contemporary strategy analysis / Robert M. Grant. - Wiley; 8 edition, 2013. -408 p.

16. Roubini, N. Crisis Economics: A Crash Course in the Future of Finance / Nouriel Roubini, Stephen Mihm. - Penguin Books, April 26, 2011. - 368 p

Kotova Nadezhda Nikolaevna. Candidate of Economic Sciences, Associate Professor. South Ural State University (Chelyabinsk).

Received 3 March 2016

\section{ОБРАЗЕЦ ЦИТИРОВАНИЯ}

Котова, Н.Н. Экономическая безопасность компании - источник конкурентного преимущества / Н.Н. Котова // Журнал Управление инвестициями и инновациями.- 2016. - №1. C.34-38. DOI:

10.14529/iimj160105

\section{FOR CITATION}

Kotova N.N., The economic security of a company - the source of a competitive advantage. Investment and innovation management journal. - 2016. - №1. pp. 34-38. DOI: 10.14529/iimj160105 